\title{
University-Industry Technology Transfer: Issues and Probable Remedies
}

\author{
Kitagaana Zaidi ${ }^{1 *} \quad$ Genza Gyaviira Musoke ${ }^{2}$ \\ 1.East African School for Higher Education Studies \& Development, Makerere University, PO box 7062 , \\ Kampala Uganda \\ 2.Faculty of Education, Makerere University, PO box 7062, Kampala
}

\begin{abstract}
The importance of technology transfer (TT) from Universities to industry cannot be overstated. Such transfer does not only stimulate development, but is also a way of bringing research into practical use. However, the issue of how Universities and industry partner for enhancement of TT activities is not well articulated. This study attempts to answer the following questions: How does policy on intellectual property rights affect TT from Universities? How does government funding affect TT from Universities? This research highlights the mechanisms adopted by Ugandan Universities for TT and the avenues for protecting intellectual property rights. It is hoped that the findings of this study will provide useful lessons to policy makers who are concerned with evaluating the effectiveness of TT from Universities. The Endogenous Growth Model was used to assess this TT. The research project was a qualitative descriptive single case study using Makerere University as a case institution. The Nvivo 9 data analysis technique was employed to organize and analyse the data. Findings indicate that inadequate funding; problems with ownership of intellectual property, lack of ethics by faculty and researchers, low motivation of staff and conflict of interest are the major impediments to University-industry TT in Uganda. The study recommends increased funding for University-industry TT activities and formalization of intellectual property rights in higher education institutions.
\end{abstract}

Keywords: University, Industry, Technology Transfer, Intellectual Property Rights, Endogenous Growth Model, Technology Diffusion.

DOI: $10.7176 / \mathrm{JEP} / 11-17-06$

Publication date:June 30th 2020

\section{Introduction}

TT is a linkage process that relates the driving of an idea with the delivery channel towards the intermediate or final user (Shubert et al., 2014). For this study, TT was taken to mean the process that involves the move of knowledge generated by the University to an enterprise allowing innovation and extend its technology capacity, giving the possibility to obtain a competitive advantage in the market (Sierra et al., 2017).

Universities have for long been involved in (TT) activities which has become a strategic issue as a source of funding for University research and as a policy tool for socio-economic development. Universities vary enormously in the extent to which they promote and succeed in commercializing academic research, yet the identification of clear-cut models of TT processes is not straightforward (Guena \& Nesta, 2011). Under the TT function, the University relates with community, national and international partners to address emerging socioeconomic challenges. The partnerships advance academic development through enriching the curriculum, providing experiential learning to students and generating real time research ideas for staff and students. For Universities, typical motivations to collaborate with industry in form of TT include the improvement of teaching, access to funding, reputation enhancement, and access to empirical data from industry. For firms, the motivations to collaborate with Universities may include gaining access to complementary technological knowledge , tapping into a pool of skilled workers, providing training to existing or future employees, gaining access to the University's facilities and equipment, gaining access to public funding and incentives. Firms may also seek to reduce risks by sharing the costs of $\mathrm{R} \& \mathrm{D}$, and to influence the overall teaching and research agenda of Universities (World Bank, 2013).

\section{Technology Transfer Models}

Universities, like companies, vary enormously in the extent to which they engage in and experiment with new mechanisms to promote the commercialization of academic research, and in the extent to which they succeed in generating additional income from third stream activities. There are five approaches to TT (Tornatzky, Waugaman \& Gray 2002; World Bank, 2013; D’Este \& Patel, 2007).

First, Industry-sponsored contract research where the University agrees to accomplish specific research and the company pays the University. However, there is the challenge of background technology which the University or industry brings to the project. Additionally, small company participation in University conducted research is low in most of the countries (Tornatzky et al., 2002) and this represents a particular issue in development goals. Universities are unable to transfer technology in some large companies or between varying 
research projects at a single University (Petrick \& Reinschman, 1995). This approach also has a challenge of how to share the royalties between the researcher, faculty which provide the facilities and industry that provide the funds.

The second approach to TT is company sponsored research consortia which perform industry focused research in the University. This arrangement helps in securing long-term, large-scale funding for the University. It is easy to pick graduate students for future employment. However, small company participation is weak and there are uncertainities about how to commercialize technology emerging from consortia. When IP comes out of the work, and it is protected via patenting as copy right, all participating companies get a non-exclusive license.

Thirdly, Consulting Arrangements. This is where faculty members work as part-time employees of the company where they are engaged. This is lucrative for the faculty members involved and is intellectually stimulating. However, these arrangements are rife with conflict of interest and commitment. The consultant lecturer has parallel obligations to his full-time employer (University) that may conflict with industry obligations. This implies that he/she may not devot enough time to either the University or to the industry.

Fourthly, Licensing of University Developed Technology. This usually occurs when research has proceeded to the point that a discret invention has occured. Universities transfer tangible IP to companies embodied in patents, trade marks, copy rights and know how embodied in trade secrets. However, compensation is complex because few licenses are paid up front but involve the payment of royalties based on revenues from the future sale of goods. Yet there seems to be an insignificant investment in capacity on the part of the University.

Fifthly, Joint Development and Commercialisation of Technology. This may involve the University taking an equity piece rather than cash. Joint commercialisation implies a much more intensive and time extensive involvement on the part of the University in their partner's business. Usually, the commercialisation partner is a new company and due deligence for the University is more concerned with oversight of business development issues such as management and capitalization and not only enforcing the terms of a licensing agreement. The faculty inventor is likely to take an equity share in the enterprise. With this arrangement, the purpose is not only to transfer technology but to start a business.

However, Universities seem not to be linked to external entrepreneural support structure to energize the internal mission and vision that support these activities. More to that, large segments of the University community are likely to be opposed to joint development and commercialisation of technology. For example in one national survey in USA of 985 faculty members, only 26.5 percent of the respondents were in favour of the University taking an equity position in firms based on University research (Tornatzky et al., 2002).

\section{Theoretical Review}

Endogenous growth model (Romer, 1990; Aghion \& Howitt, 1992) have shed light on the determinants of Total Factor Productivity (TFP) growth, linking TFP growth rate to innovation. According to this model, firms produce technical knowledge which initially is private to the firm but subsequently spills over to the rest of the economy as it can be copied at no cost. With this spillover effect, an aggregate production function which would otherwise have either constant or decreasing returns to scale may exhibit increasing returns to scale allowing sustained long-run growth. An implication of this view is that a firm, when not able to innovate on its own, can benefit from the research findings of firms working along similar lines. However, as suggested by Cohen and Levinthal (1990), utilizing public domain knowledge fruitfully is not without a cost and this cost is minimal only for firms that have accumulated sufficient technological capability to absorb external knowledge.

Contrastingly, Etzkowitz et al. (2000) observe that the concept of the entrepreneurial

University encompasses a 'third-mission' of economic development. Serving society is becoming a coherent domain of the University and entrepreneurial Universities are active in that process (Mets, 2009). Such universities, Mets (2009) notes, interlink three missions: education, research and serving society. Institutionally, they are characterised by the creation of technology transfer offices, the active patenting of University research, the creation of entrepreneurial competences and mind-sets among University members, the active position to produce and utilise University knowledge for the socio-economic transformation of society and the creation of an entrepreneurial environment inside and around the University (Mets, 2009, p. 2-3). The transformation from a teaching and research institution to an institution that pursues teaching, research and economic development, Etzkowitz (2003) observes, denotes a second academic revolution.

\section{The Case of Makerere University}

Makerere University was chosen to be the case study because recently it has repositioned itself as a University where research, teaching and knowledge transfer partnerships and networking are the core functions (DdumbaSsentamu, 2017; Makerere, 2016; Nawangwe, 2017). The institution focuses more on knowledge production to support evidence based decision making and to ponder about the growth of Uganda's economy desired in Vision 2040. The University's vision is to be the leading institution for academic excellence and innovation in Africa (Bailey et al., 2011). Additionally, the strategic direction of Makerere University's current strategic plan 
(2008/09-2018/19) includes the following: A research-driven University where research and teaching/learning are mutually reinforcing; and knowledge transfer partnerships and networking (Alinaitwe, 2018, p.40).

At the forefront of the University's TT is the College of Engineering, Design, Art and Technology (CEDAT) whose mission is to provide excellent teaching and learning; innovative, cross-disciplinary research and knowledge transfer partnerships Students and staff in this College are involved in innovative projects for example; There is the solar irrigation pump which is bound to solve problems associated with the effects of climate change; CEDAT makes cheap and efficient sanitary pads from papyrus, waste paper and sell them to rural disadvantaged communities at affordable prices. This innovation is relevant because ealier research has found that many disadvantaged primary school girls absent themselves from school during menstrual periods. The absenteeism leads to poor academic performance and subsequent dropping out of school; The Community Wireless Resource Centre (CWRC) is an initiative under the department of electrical engineering. The primary objective of the CWRC is to provide sustainable internet connectivity infrastructure by means of wireless technology. The CWRC takes on fourth year students doing research projects in the areas of community wireless networks such as a band width management.

Another project is the Centre for Technology Design and Development (CTDD) established in 2002. The main activities of CTDD are development and application of innovative technology, research and technology transfer with the aim of uplifting socio-economic development of Uganda in sustainable manner. The CTDD is the backbone link between the community, industry and CEDAT.

\subsection{The Problem}

Although both University and industry stand to gain immensely from TT, the reality on ground seems to be different. University researchers, seem to be motivated to publish research results as fast as possible while industry is concerned about secrecy and misalignment of expectations with regard to intellectual property (IP) rights and making a profit from them. The Industrial sector seems to be concerned with short-term goals, University officials and academic staff seems to prioritize long-term partnerships. Academics have the tendency to look at multiple angles of an issue, while industry is concerned with solving specific problems with commercial implications. Therefore most University-industry partnerships are contractually bound and shortterm, with very little room for basic research or more creative types of investigation. Some academics seem to believe that industry does not have an intellectual understanding of University structures and activities (Sa, 2013). Yet a robust TT function is an essential ingredient and it needs to be appropriately staffed and funded. This however seems not to be so, hence the need to examine University-Industry TT of Ugandan Universities taking Makerere University as the case institution.

\subsection{Research Questions}

The study intended to answer the following questions:

1. How does policy on intellectual property rights affect technology transfer from Universities?

2. How does government funding of Universities affect technology transfer?

4.2.1 How policy on intellectual property rights affects technology transfer from Universities

Universities across the world are confronted by a very delicate question of how to strike the right balance between publishing their inventions and patenting them (World Bank, 2013). In a scenario where industry provides funds for research, University utilises its manpower and infrastructure to conduct that research. In this case, there is a triangular claim over the ownership of resulting IP and the issue is often mired in conflict (Sierra et al., 2017). The National IP protection law secures the value added by an individual to a product or service and gives them an exclusive right to exploit their IP. This is an incentive to inventors to further engage in innovations. It is an asset that can be leveraged to attract financing.

In a study carried out by panagopoulos in USA, it was found that decision of the firm to collaborate with a University will depend on the opportunity cost associated with sacrificing its own research initiatives to collaborate with another organization. The key factor in determining the magnitude of the opportunity cost is the degree of intellectual property protection (Link, Scott, Siegel, 2003, p.12). Companies may choose minimal IP protection since they expect to derive benefits from enhanced knowledge spillovers.

In Uganda, the Uganda Registration Services Bureau (URSB) is the national IP office that administers laws on IP ( Amamukirori, 2017). URSB has spearheaded the process of formulating a National IP policy and a national steering committee was constituted, consultations were carried out and a draft was prepared. A technology and innovation support centre was established to facilitate access to technical information necessary to support scientific research and technology transfer. Registration of IP rights has been automated leading to efficiency in the registration process. An IP enforcement unit against counterfeits and piracy has also been put in place. Yet TT from University to industry seems to be slow (Amamukirori, 2017).

In earlier years, Makerere University researchers placed higher priority on publishing their findings, but drive for U-I collaboration has put pressure on them to shift such priority towards protecting their IP through 
patenting. Issues in sharing of royalty relate to valuation of contributions and division of the cost burden.

In addition, implementation of the IPM policy is envisaged to increase income arising from research activities, as well as increase the contribution of Makerere to the wellbeing of society. However, Universities in Uganda do not seem to have a clear and coherent set of policies for managing their IPRs (UNESCO, 2015). This does not suggest that inventions of Universities should be more protected. Experience in the OECD countries suggests that excessive protection is detrimental to the maximum use of the knowledge developed in academic communities (Nezu, 2005).

4.2.2 How does government funding of Universities affect technology transfer?

Public Universities in Uganda have been largely state funded, with about three quarters of the total expenditure being borne by the government (NCHE, 2010). The political and state control over the governance of Universities has impacted on their financing. A study by Court (1999), supported by the World Bank and the Rockefeller Foundation, emphasised that the government subvention to Makerere University had actually remained relatively constant in absolute terms, but had declined markedly with regard to the capital contribution in the face of scarce and declining resources. The report recommended a measure of autonomy from government in both policy and funding as an essential pre-requisite for the development of alternative financing arrangements and the retention of funds derived from these sources. The study did not suggest the alternative means of generating funds to support research and innovation.

In a few cases, most of these funds are integrated in the general University budget. A strategy to integrate donation contributions by various partners into the University programme seem to contribute to the financing of the deficit gaps of Makerere University. A study by Bailey et al. (2011) indicates the dwindling financing (per unit) of Makerere University but does not provide a solution on how additional funds can be generated (Makerere University, 2014).

Table 1: Makerere University Government Income (1999/2000-2006/2007)

\begin{tabular}{|l|c|c|c|}
\hline Academic year & $\begin{array}{c}\text { Government income } \\
\text { in Ugandan Shilling } \\
\text { (USh) (Thousands) }\end{array}$ & $\begin{array}{c}\text { Government income } \\
\text { in USD }\end{array}$ & Exchange Rate \\
\hline $1999 / 00$ & 22973829 & 13008963 & 1766 \\
\hline $2000 / 01$ & 23200000 & 12821221 & 1810 \\
\hline $2001 / 02$ & 27742000 & 14971398 & 1853 \\
\hline $2002 / 03$ & 27526750 & 14233066 & 1934 \\
\hline $2003 / 04$ & 26590262 & 15290547 & 1739 \\
\hline $2004 / 05$ & 36653004 & 20980540 & 1747 \\
\hline $2005 / 06$ & 35102427 & 20104483 & 1746 \\
\hline $2006 / 07$ & 36399716 & 19977890 & 1822 \\
\hline
\end{tabular}

Source: Bailey et al. (2011)

Table 1 above shows that the total income received by Makerere University from government increased from USD 13,008,963 in 1999/2000 to USD 19,977,890 in 2006/07. Over the same period, state allocations as a proportion of total income decreased from almost two-thirds (63.53\%) in 2000 to a third (33.88\%) in 2006 (see figure 1 below). 
Figure 1: Makerere University income by source as a percentage of total income $(2000-2006)$

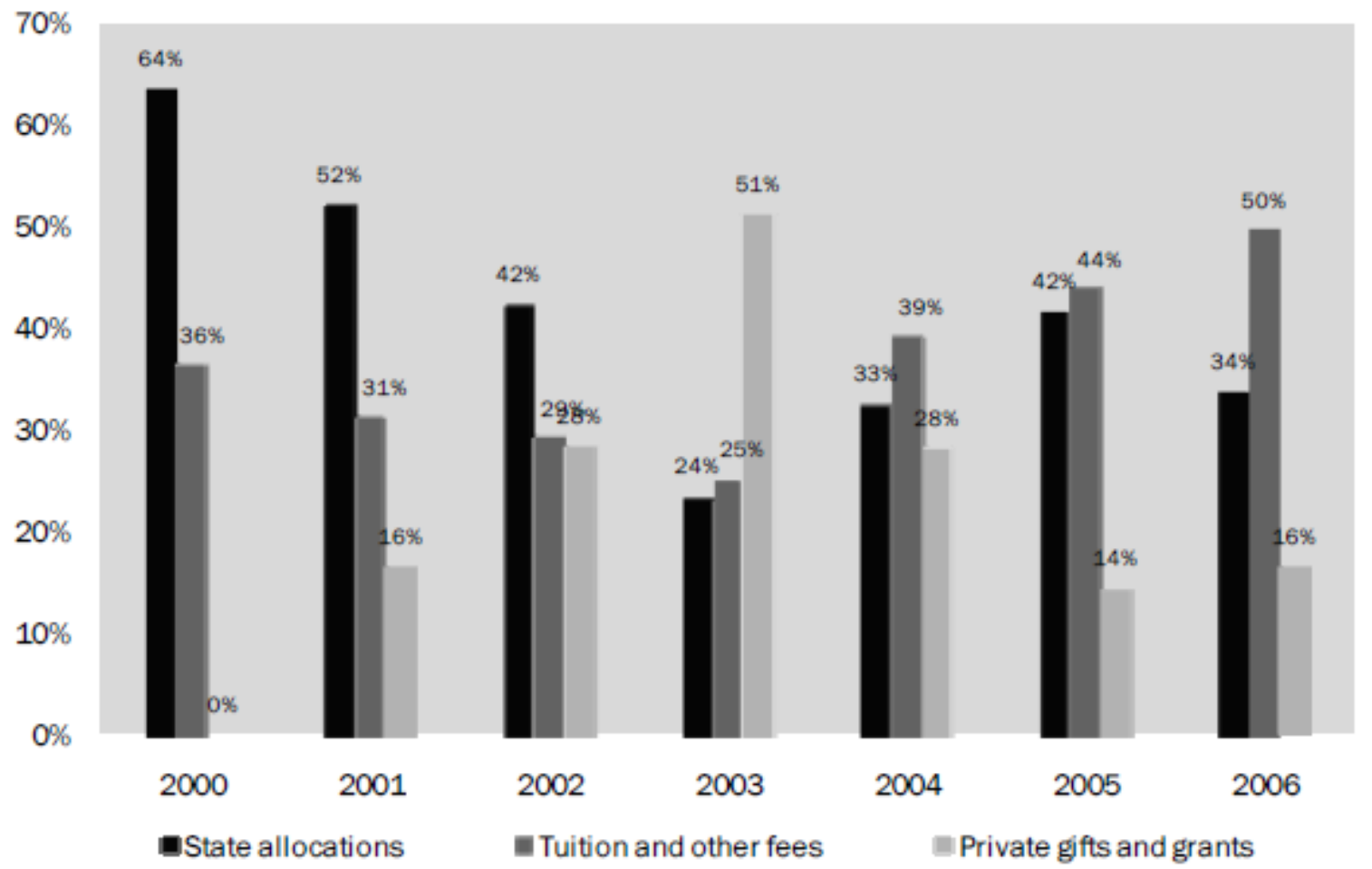

Source: Bailey et al. (2011)

The figure above indicates that public financing of Makerere University decreased from $64 \%$ in the year 2000 to $34 \%$ in 2006 implying that the University could not carry out meaningful research and innovations. The government presumed to get additional funds from donors. Past research indicate that lack of funding for research and knowledge production is as a result of the absence of a national strategic plan for research (Alinaitwe, 2018). Although the absolute figures indicate an increase in money provided by the government for the running of various programmes of Makerere University, the funding for research and innovation has gone down (Makerere University, 2014).

The University's current strategic plan highlights that limited and declining government funding for higher education will work against Makerere achieving its strategic objectives (Makerere University, 2008a: p.9, 27). It was anticipated by the framers of the University's Strategic Plan that funds for research would be generated by resource mobilization unit and various planning units of the University. However, according to the University Web (http://mak.ac.ug/index), the institution's sources of research funding from government and students' fees contribute only $1 \%$ which does not seem to be substantial to undertake research implying that technology transfer flows at a slow pace because of limitations in innovation.

Makerere University's financial statements suggest that it had Uganda shillings 15,116 million in research funding. This was equivalent to USD 800,000 at market exchange rates. These amounts, when divided by Makerere's total permanent staff become USD 700 per academic which implies that Makerere was not able to fund its research activities adequately (Bailey et al., 2011).

\section{Methods}

The study was carried out using a single case study design that utilised qualitative research methods. Makerere University, College of Engineering, Design, Art and Technology (CEDAT) was the focus. This is because TT at Makerere has been highest at this college (Alinaitwe, 2018). CEDAT has three schools: Engineering; The Built Environment and then School for Industrial and Fine Arts. The school of Engineering has three departments: Civil and Environmental; Electrical and Computer and then Mechanical. The school of the Built Environment has three departments: Architecture and Physical Planning; Geometics and Land Management; Construction Economics and Management. The population of study comprised the three deans of schools, one head of department from each of the three schools. These were purposively selected. This sampling technique enabled us to identify and select information rich cases. The data for this study were generated through document reviews, face-to-face semi-structured interviews and observation. We as researchers personally visited the selected participants as required by qualitative research. The choice of methods was influenced by the nature of the research problem, the purpose of the study and the desire to generate detailed data. Out of the six targeted 
respondents, we managed to interview five as one of the deans was reported to be out of the country. In this study, the organisation of data sources, the coding and searching of the data were carried out using NVivo 9. After transcribing the interview recordings, the researchers replaced the interviewees' actual names with participants $(\mathrm{P})$ numbers to ensure the anonymity of the interviewees and thereafter created a project in NVivo and imported all the data sources into the project. Qualitative research seeks to produce credible knowledge of interpretations processes and understanding, with an emphasis on uniqueness and context. There are four criteria of research trustworthiness developed by Lincoln and Guba (1985) which has been widely cited in the social science research methods literature (e.g. Kalof, Dan \& Dietz 2008; Bryman, 2012) to evaluate the quality of qualitative research. Credibility deals with the accuracy of data to reflect the observed social phenomena. Transferability refers to the level of applicability of the study findings into other settings. As suggested by Lincoln and Guba (1985), a rich and thick explanation of research sites and characteristics of case organisations should be provided to enhance transferability. Dependability corresponds to the notion of reliability which promotes repeatability (Wahyuni, 2012). Confirmability refers to the extent to which others can confirm the findings in order to ensure that the results reflect the understandings and experiences from observed participants, rather than the researcher's own preferences. The researchers adhered to this criterion.

\section{Findings}

The findings of this study show that TT at Makerere University suffers from a number of factors, among which is improper management of IP; absence of mechanism to track TT; conflict of interest and then under funding for University research activities.

Intellectual Property Rights management remains a complex issue for successful TT. Currently, the allocation of ownership and licensing revenues is determined basically by Makerere University using IPR law of 2008. A strong foundation of University-industry partnership depends on and can be accentuated to a great extent by the Technology Transfer Office (TTO). To thrive, it is imperative that a TTO should have appropriate staffing, clearly articulated mission, a customer-friendly orientation, clear policies and procedures, and a supportive University culture (Bhattacharya, 2005, p. 413).

According to some of the participants, TT managers have limited knowledge about IP management. The TTOs are not well managed and in some units they are non existent, there are no expertise managers in intellectual management law. Participant Pl reasons that majority of the academics in the college lack the culture and disposition to link with the productive sector. This, he says is due to the poor University policy of promotion of academic staff. The evaluation of academic staff is dependent on traditional parameters and of number of years at a position and not the academic growth. Professors therefore dedicate more time to basic research and publish their findings because this gives them a more reliable path for promotion and hence salary enhancement. He complains that the college does not have suitable institutional structure to commercialise its technologies. He laments that his school does not have designated TT managers and no budget has been earmarked for this cause.

Participant P2 acknowledges that his department undertakes interdisciplinary research with other departments and that an attempt was made sometime back to start a technology innovation centre although this has not been actualised yet. This means that technology diffusion from the University to industry is low. He further complains about the mandate of the University mission which is largely to teach as opposed to community engagement. He says "University policy is narrow and there is need to change many things in the running of the University. TT at Makerere University is constrained by the appointments and promotions policy for the academic staff which is unbalanced in favour teaching. For instance, the University awards each member of its academic staff a maximum of 2 points and 3 points percent for his or her innovations and contributions to the external communities respectively. Contrastingly, the University awards each member of the academic staff a maximum of 25 points for his or her publications. We need to restructure the mandate of the University from focus on teaching to community outreach. The role of the lecturer has to change and focus on contract research for profit and they should begin working on start-ups" he advises.

Participant P3 advocated for a structual change in management, research, teaching and community outreach and he is in for " an open door policy on interdisciplinary research" He complains about University policy on teaching where classes are big even for sciences. Members of the academic staff have heavy workloads and as a result, they cannot find adequate time to carry out meaningful TT activities. The University's policy on the appointment and promotion of the academic staff states that the maximum workload for a teaching member of the academic staff is 10 hours per week. This participant argued that the allocated workload leaves the teaching staff with hardly any time to participate actively in TT activities. He also mentions existence of limited facilities for industrialists e.g workshops as a major impedment to the TT. He advocates for "vocationalising University education, changing policy on skills acquisition and provision of space where University researchers and students can work with the informal sector in areas of fublication." Before graduation, he reasons students should have some practical skills from the industrial sector. His observations are in line with those of Wu (2015) who found that acquisition on new experiences or knowledge should aim at improving products, services and the 
productive processes of the enterprises.

Participant P4 says that although the commercialisation of research inventions is still low at the college, the college has already established some organisational structures e.g the Technology Development and Transfer Centre; and the National Software Incubation Centre to support the development, transfer and commercialisation of technology. Besides the organisational structures, the University has an intellectual property management (IPM) policy, whose objective is to stimulate and support innovative thinking among students and staff and to enable ownership and efficient management of intellectual assets and innovations produced at the college. Furthermore, spin-off companies started by members of the academic staff based on their research activities and results are helping in the TT. One notable example is Technology for Tomorrow (T4T), a spin-off company . The company focuses on low-cost, easy-to-maintain, easy-to-apply and environmentally friendly technologies in areas such as housing and sanitation. T4T's flagship product is MakaPad, a low-cost sanitary pad made from papyrus and waste paper. The company also manufactures products such as, incinerators, water heaters, hybrid stoves, granaries, bio-sand water filter, interlocking stabilised soil blocks for building purposes and latrines. In this cause, T4T partnered with United Nations High Commission for Refugees who spotted the ingenuity of professors at CEDAT and bankrolled them.

Another participant regrets lack of ethics by academic staff and researchers where some of them do not declare their inventions formally. There is a complaint about the poor University policy on research, teaching and community outreach where teaching is given priority at the expense of research and innovation for TT. The participant complains that the classes are too big for scientists and the teaching load well above the NCHE recommendations. He also complained about the low motivation of staff and this partly explains why some staff do their TT not following formal set University guidelines. More to that, the University has limited facilities for industrialists. The laboratories and workshops do not have the required tools where students could innovate. This means that some of the University innovations are on paper.

\section{Discussion}

Although commercial gains are not always the goal for Universities, patenting is advisable for the purpose of maintaining control over how their inventions will be utilized. At least, they can prevent someone else from taking over the inventions and claim patents for themselves. Thus, the management of IPRs is the central issue in the advancement of TT. Views are different on how ownership should be distributed between those who conduct the research and those who fund it, or among the research institutions, the individual researchers and the government. The US model, established by the Bayh-Dole Act of 1980, allows the performer of the publicly funded research, namely Universities, to file patents on the results of such research and to grant licenses to third parties (Bayh-Dole, 1980). Globally, this issue of how to allocate ownership of IPRs is a subject of on-going debate.

Currently, the allocation of ownership and licensing revenues of IP is determined basically by individual Universities. At Makerere, the aim of Makerere University Intellectual Property Policy is to stimulate and support innovative thinking among students and staff, and to enable ownership and efficient management of intellectual assets and innovations produced at Makerere (Marerere University, 2008). Makerere University CEDAT is engaged in software licensing, where technology developers get a royalty. This is done in collaboration with other Universities. According to the IPRs policy, University Inventions developed in whole or in part through the utilization of University resources or facilities should not be availed to the general public (Makerere University, 2008).

Improper management of IPRs may result in unfair benefits for some private businesses or loss of revenue for governments that offered support through taxpayer money. At the present, so much of the substance of cooperation is left to the bilateral negotiation between University and company, that there is real risk of losing clarity and consistency among Universities, companies and projects. Therefore, government and Universities should keep track of projects and activities that involve TT. Such information should periodically be made public in order to ensure proper and equitable use of research results (Nezu, 2005).

The NCHE (2010) called for reforming the financing of higher education to ensure that public funds are only committed to key strategic areas and disciplines, instead of institutions focusing on all academic components of higher education. The strategy requires Universities to strengthen their financial bases through multiple funding sources. Makerere University's major sources of funding are government, institutional contribution and donor funding ( Makerere University, 2017). Documented evidence from most parts of the world suggests that public funding can support high quality tertiary education only when the system is relatively small and hence inevitably elitist (Court, 1999). Large scale, or mass, education at the tertiary level requires significant private supplementation. The challenge, therefore, is to attract private resources while protecting both quality and equity of access.

Etzkowitz et al. (2000) noted that funding shortages pushes the University to carry out some TT activities. Accordingly, the recent trends in the TT at Makerere University is a core function of the institution. Since the 
1990's Makerere University relied on the government for funding (Oboko, 2013), the character of its finances, Mamdani (2007) observes, "reflected the budgetary crisis in government. Although the national financial crisis was responsible for the financial crisis at the University, the sharp decline in state funding of University education was a result of not only the national crisis but also a public policy based on the World Bank's argument that the rate of return on investment in higher education was much lower than that of primary and secondary education (Mamdani, 2007).

Due to the above reforms, the University has shifted from a state of reliance on the state for funding to a situation in which a growing proportion of University finances is sought from auxiliary sources such as TT.

\section{Conclusion}

The findings of the study conclude that TT from Universities is determined to an extent by the amount of financial resources injected into the University by the government together with the traditional indicators such as patents. In order to introduce new products and processes, industries must have the capacity to innovate. Efforts to stimulate innovation are unlikely to yield a high return if the efforts are not complemented by a sufficient stock of human capital. Advanced human capital not only improves the possibility of industries engaging in innovation, but the skills of the workers also increase the industry's ability to absorb new knowledge and technologies. Besides formalized knowledge, tacit knowledge is an important component of innovation. Absorptive capacity may be developed through the accumulation of experience and this kind of industry knowledge may be measured by the work experience of the employees. Highly educated employees encourage engagement with other individuals with similar competencies outside the industry. The response from the participants confirms the need for improving Universities' institutional capacities to develop and support TT. There is acknowledgement that more professional competence is needed to deal and appropriately market knowledge produced by University faculty and students. It has been confirmed that institutions need qualified staff to manage and support TT. Moreover University involvement and success in TT is highly dependent on the nature of the organizational culture of the institution. The shared values, knowledge, rewards and incentives of a University can either facilitate or impede TT and industry partnership.

\section{Recommendations}

In line with the findings and conclusions of this study, the researchers recommend the following:

1. Within Universities, stimulating interactions across teams of researchers with complementary expertise should be encouraged, regardless of their disciplinary or departmental affiliation.

2. Interdisciplinary research programs that include industry partners should be encouraged in Universities. Those programs might be housed in dedicated research centres including business representatives in their Advisory Boards.

3. Universities should take advantage of their position as public institutions to exercise the role of public spaces for open-ended debate on local economic, social, and technological challenges. This can be done through organising and host events bringing together academics and industrial representatives, along with other relevant stakeholders. Informal social interactions can also be helpful in sparking dialogue and working relationships. Purposefully using University facility for events and social engagements can facilitate such interactions.

4. There is need to revise the IPR policy of 2008 to motivate researchers and students to engage in innovations

5. The private sector should be encouraged to work with Universities in the enhancement of TT.

However this study was limited by the fact that only one institution and one college were used. One of the participants had recommended that we as participants interact with lecturers and administrators in the College of Agriculture and Environmental Science. Even then, the study remains valuable for the benefit of Universities, government and the productive sector.

\section{References}

Amamukirori, G. (2017), Intellectual Property Day. Improving Lives through Innovations. April $26^{\text {th }}$ New Vision Publishers, Kampala.

Alinaitwe, H. (2018), Makerere University Taking the Lead in the Realization of Vision 2040. In New Vision, Monday, $27^{\text {th }}$ August 2018. P.40

Bailey, T., Cloete, N., \& Punday, P. (2011), Universities and economic development in Africa. Case study: Uganda and Makerere University. HERANA, CHET.

Bryaman, A. (2012), Social Research Methods, $4^{\text {th }}$ edn, Oxford University Press, New York.

Bayh-Dole. (1980), Patent and Trademark Amendments Act of 1980, Pub. L. No. 96-517, 35 U.S.C.200-212.

Bhattacharya, P. (2005), Technology transfer from a technical University: A case study of IIT Delhi. Journal of Intellectual Property Rights, 10(5), 413-416. 
Bozeman, B. (2000), Technology transfer and public policy: A review of research and theory. Research Policy, 29(4-5), 627-655.

Cohen, W. M. \& Levinthal, D. A. (1990), Innovation and Learning: the Two Faces of R\&D, Economic Journal 99: $569-96$

Court, D. (1999), Financing Higher Education in Africa: Makerere, the Quiet Revolution. The World Bank and The Rockefeller Foundation.

Ddumba-Ssentamu. (2017), Makerere University Handover Report to the Incoming Vice Chancellor. 14th september, 2017.

D'Este., \& Patel, P. (2007), University-industry linkages in the UK: What are the factors underlying the variety of interactions with industry? Research Policy 36, 1295-1313.

Etzkowitz, H. (2003), Research groups as 'quasi firms': The invention of the entrepreneurial University. Research Policy, 32 (1): 109-121.

Etzkowitz, H., \& Leydesdorff, L. (2000), The dynamics of innovation : from National Systems and "Mode 2" to a Triple Helix of University - industry - government relations. Science and Technology, 109-123.

Geuna, A. \& Nesta, L. J. J. (2011), 'University patenting and its effects on academic research: The emerging European evidence', Research Policy, 35(6), 790-807.

Kalof, L., Dan, A., \& Dietz, T. (2008), Essentials of Social Research. McGraw-Hill, New York.

Kasozi, A. (2018), Makerere's New Rwendeire Report needs a second look. In New Vision March $14^{\text {th }}$, New Vision Publisher, Kampala

Kaymaz, K., \& Eryiğit, K.Y. (2011), Determining Factors Hindering University-Industry Collaboration: An Analysis from the Perspective of Academicians in the Context of Entrepreneurial Science Paradigm.

Kumar, P., \& Gupta, R. (2017), The Roadmap for Enhancing University-Industry Research Collaboration in India. Indian Journal of Public Administration. 63 (2) 196-227. SAGE Publications.

Lincoln, Y.S., \& Guba, E.G. (1985), Naturalistic Inquiry, Sage Publications, Beverly Hills, California.

Link, A. N., Siegel, D. S., \& Bozeman, B. (2007), 'An empirical analysis of the propensity of academics to engage in informal University technology transfer'. Industrial and Corporate Change, 16(4), 641-655.

Makerere University. (2016), Annual Report. Directorate of Planning and Develpoment.www.mak.ac.ug/http://pdd.mak.ac.ug.

Makerere University. (2008), Intellectual Property Management Policy. Kampala.

Makerere University. (2014), Annual Report 2013. Planning and Developing Department: Makerere University: Retrieved from http:// pdd.mak.ac.ug.

Makerere University. (2012c), Innovation Catalogue 2012. College of Agricultural and Enviromental Sciences. CAES.

Makerere University. (2008), Strategic Plan 2008/09-2018/19. Kampala: Planning and Development Department, Makerere University.

Mamdani, M. (2007), Scholars in the marketplace: The dilemmas of neo-liberal reform at Makerere University, 1989-2005. Kampala: Fountain Publishers.

Marotta, D., Mark, M., Blom, A \& Thorn, K. (2008), Human Capital and University-Industry Linkages' Role in Fostering Firm Innovation: An Empirical Study of Chile and Colombia World Bank Washington D.C.

Mets, T. (2009), Creating business model for commercialization of university research. Management of Organizations: Systematic Research, 51(1/2), 1-13.

National Council for Higher Education. (2010). The state of higher education and training in

Uganda 2010: A report on higher education delivery and institutions. Kampala: NCHE.

Nawangwe, B. (2017), Makerere University Monthly Media Briefing. 30 ${ }^{\text {th }}$ October, 2017.

Nezu, R. (2007), Overview of technology transfer, intellectual property rights and effective University-industry partnerships in China, India, Japan, Philippines, The Republic of Korea, Singapore and Thailand. In Technology transfer, intellectual property rights and University-industry partnerships: Geneva: World Intellectual Property Organisation Report.

Oboko, M. B. (2013), Funding higher education in Uganda: With special emphasis on donor's role and contribution of national communities approaches. In D. Teferra (Ed.), Funding higher education in SubSaharan Africa (p.257-263). London: Palgrave Macmillan.

OECD. (2010), Innovation Vouchers. OECD Policy Brief, OECD, Paris.

Petrick, I. J. \& Reischman, M. M. (1995), The Inherent Tension of University- Industry Master Agreements. Proceedings. Technology Transfer Society Annual Meeting. Research Policy.

Sa, C. M. (2013), Perspective of Industry's Engagement with African Universities. AAU. Accra.

Shubert, P., Killian, T., \& Bjorn, N. (2014), I am an engaged scholar: a typology of IS researchers' engagement in research with industry, procedia technology 16.

Sierra, L. M. P., Vargas, M. E. M., Torres, V. G. L. (2017), An institutional framework to explain the University-Industry Technology Transfer in a Public University of Mexico. Journal of Technology 
management and Innovation. ISSN: 0718-2724.

Tornatzky, L., Waugaman, M. P. A., Gray, D. O. (2002), Industry - University Technology Transfer: Models of Alternative Practice, Policy and Programmes. A benchmarking report of the Southern Technology Council. Grants EPS-9819351

UNESCO. (2015), UNESCO Science Report. Towards 2030.

World Bank. (2013), Promoting University. Industry Collaboration in Developing Countries. Policy Brief.

World Intellectual Property Organisation. (2012), University initiative program (Publication No. 1033E). Geneva: WIPO.

World Intellectual Property Organisation (WIPO). (2006), Developing Framework to Facilitate University Industry Technology Transfer.

Wu, Y., Welch, E., \& Huang, W. (2015), Commercialization of University inventions: Individual and institutional factors affecting licensing of University patents. Technovation 36-37.

Zuniga, P. (2011), The State of Patenting of Reasearch Institutions in Developing Countries: Policy Approches and Practices WIPO Economic Research Working Paper 4, World Intellectual Property Organisation. Geneva. 